$M_{1} M_{2} N_{121} P_{13}$ are given by respectively $1,2,3,4,5,6$ independent linear relations between the variables, so that a suitable combination of these types leads to a substitution of class $2^{2 n m}-2^{n t}$. For $G_{\lambda^{\prime}}$, we note that $L$ and $M_{1} M_{m} N_{m 11}$ (in the notations of Linear Groups, page 201) leave fixed the letters with $\xi_{m}=\eta_{m}=0, \xi_{m}=\eta_{m}=\xi_{1}=\eta_{1}=0$, respectively.

9. Theorem VII. The subgroup $* J_{\lambda}$ of index two under $G_{\lambda}$ contains substitutions of classes $2^{2 n m}-2^{2 n j}(j=0,1, \cdots, m-1)$ exclusively.

I have established this theorem for low values of $m$ with $n$ arbitrary; but as the method seems unwieldy for general $m, \mathbf{I}$ suppress the proof. This remarkable theorem in connection with Theorem VI furnishes an analogue to Theorem V.

The University of Chicago, February 10, 1905.

\title{
NOTE ON A PROBLEM IN MECHANICS.
}

BY MR. A. M. HILTEBEITEL.

(Read before the American Mathematical Society, February 25, 1905.)

IN an article $\dagger$ inserted in the twenty-eighth volume of the Giornale di Matematiche, $末$ on the separation of the variables in the equations of the motion of a body acted upon by two fixed centers of force, the author, Dr. Carlo Bonacini, states with inadequate proof that the separation of the variables in the equations of motion is possible only when the two forces vary inversely as the squares of the respective distances of the body from the fixed centers.

That the variables can be separated when the forces vary inversely as the squares of the distances has been known since

* Linear Groups, p. 206, \& 205.

$\dagger$ "Sulla separazione delle variabili nelle equazioni del moto di un punto soggetto all'azione di due centri fissi," Giornale di Matematiche, vol. 28 (1890), pp. 132-137. (Date of article, May, 1889.)

$\ddagger$ The object of the paper is given by the author in the following words: " Noi dimostreremo a questo proposito che la separazione delle variabili nelle equazioni del moto è possibile solo quando le due forze sono Newtoniane." 
the classic memoirs of Euler,* but it is not true that this is the only law of force for which separation of the variables is possible. To convince one's self of the latter fact it is only necessary either to refer to Lagrange's second memoir $\dagger$ on this problem, where it is shown that the variables are separable when the law of force is a certain linear combination of the inverse square and the direct distance, $\$$ or to remark that in the case of forces varying directly as the distances the variables are separated in the differential equations of the motion, expressed in ordinary rectangular coördinates.

It is the object of the present note to point out the error in Dr. Bonacini's reasoning and to show that Lagrange's form of the forces just referred to is the most general case admitting of the separation of the variables, when the forces are functions only of the respective distances.

Let $K_{1}, K_{2}, M$ represent the two fixed centers and the moving point respectively. Let $r_{1}$ and $r_{2}$ denote the distances $K_{1} M$ and $K_{2} M$ respectively. Finally, let $U\left(r_{1}\right)$ and $V\left(r_{2}\right)$ denote the forces acting upon $M$ and constantly directed toward the centers $K_{1}$ and $K_{2}$ respectively. Lagrange showed in the above mentioned memoir that the variables can be separated, whether

* Euler: "De motu corporis ad duo virium centra attracti," St. Petersburg Memoirs for 1764, published 1766, vol. 10, pp. 207-242.

"Un corps étant attiré en raison réciproque quarrée des distances vers deux points fixes donnés, trouver les cas ou la courbe décrite par ce corps sera algébrique," Berlin Memoirs for 1760, published 1767, pp. 228-249.

"De motu corporis ad duo centra virium fixa attracti," St. Petersburg Memoirs for 1765, published 1767, vol. 11, pp. 152-184.

$\dagger$ Lagrange : "Recherches sur le mouvement'd'un corps qui est attiré vers deux centres fixes," Turin Memoirs for 1766-69, vol. 4, pp. 215-243 ; Cuvres vol. 2 (1868), pp. 94-121.

$\ddagger$ Among other memoirs appearing before 1889 (the date of Bonacini's paper) which make mention of the fact that the variables are separable when the forces are of this nature, are the following :

Liouville: "Sur quelques cas particuliers où les équations du mouvement d'un point matériel peuvent s'intégrer," Journ. de Mathématiques, vol. 11 (1846), pp. 345-378; vol. 12 (1847), pp. 410-444; note vol. 13 (1848), pp. 34-37.

Serret: "Mouvement d'un point materiel attiré par deux centres fixes, en raison inverse du carré des distances," Journ. de Mathématiques, vol. 13 (1848), pp. 13-34.

Desboves: "Sur le mouvement d'un point matériel attiré en raison inverse du carré des distances par deux centres mobiles," Journ. de Mathématiques, vol. 13 (1848), pp. 369-396.

Bertrand: "Mémoire sur quelque-unes des formes les plus simples que puissent présenter les intégrales des équations différentielles $d$ 'un point matériel," Journ. de Mathématiques, ser. 2, vol. 2 (1857), pp. 113-140.

Jacobi: "Anziehung eines Punktes nach zwei festen Centren," Vorlesungen über Dynamik, No. 29 (read 1842-43), 1866 ; Gesammelte Werke, Supplement (1884), pp. 221-231. 
the motion takes place in a plane or in space when the forces are of the form

$$
U=2 c r_{1}+\frac{c_{1}}{r_{1}^{2}}, \quad V=2 c r_{2}+\frac{c_{2}}{r_{2}^{2}},
$$

where $c, c_{1}, c_{2}$, are any constants. We shall show that these are the most general forms of the functions $U$ and $V$ for which the variables are separable. To this end we shall make use of results established by Liouville and Morera and employed by Dr. Bonacini in his argument.

Liouville, in the memoirs mentioned above, proved that separation of the variables is possible whenever the linear element and the potential function have the forms

$$
d s^{2}=\lambda\left(m d \mu^{2}+n d \nu^{2}\right), \quad P=[f(\mu)+F(\nu)] / \lambda
$$

respectively, where $m$ and $f(\mu)$ are any functions of $\mu, n$ and $F(\nu)$ any functions of $\nu$, and $\lambda$ is a function of $\mu$ and $\nu$ in which the variables $\mu$ and $\nu$ are separated. He showed further that the linear element will take this form only for elliptic coördinates and their limiting forms, namely, cartesian, parabolic, and polar coördinates.

Later Morera* showed that the conditions (2) are also necessary for the separation of the variables in the equations of the motion of a point in a plane.

Now, retaining the method and notation of Dr. Bonacini's paper, let $\sigma$ and $\delta$ be the plane elliptic coördinates and $\alpha$ the distance between the foci. Then the linear element takes the form

$$
d s^{2}=\frac{\sigma^{2}-\delta^{2}}{4}\left(\frac{d \sigma^{2}}{\sigma^{2}-a^{2}}-\frac{d \delta^{2}}{\delta^{2}-a^{2}}\right),
$$

and the potential function must have the form

$$
P=4 \frac{f(\sigma)+F(\delta)}{\sigma^{2}-\delta^{2}} \equiv \frac{f\left(r_{1}+r_{2}\right)+F\left(r_{1}-r_{2}\right)}{r_{1} r_{2}},
$$

and must evidently satisfy the partial differential equation

$$
\frac{\partial^{2} r_{1} r_{2} P}{\partial r_{1}^{2}}=\frac{\partial^{2} r_{1} r_{2} P}{\partial r_{2}^{2}}
$$

* "Sulla separazione delle variabili nelle equazioni del moto di un punto materiale su una superficie," Atti della $R$. Accad. di Torino, vol. 16 (188081), pp. 276-295. 
Assuming the motion in the problem of two fixed centers to take place in a fixed plane passing through the line of centers, the two fixed centers themselves being taken as the foci of the system of elliptic coördinates, then it is required to find what the forms of $U$ and $V$ must be in order that the function

$$
P=U\left(r_{1}\right)+V\left(r_{2}\right)
$$

may satisfy the equation (5).

From (5) and (6) we have

$$
\frac{\partial^{2}\left\{r_{1} r_{2}\left[U\left(r_{1}\right)+V\left(r_{2}\right)\right]\right\}}{\partial r_{1}^{2}}=\frac{\partial^{2}\left\{r_{1} r_{2}\left[U\left(r_{1}\right)+V\left(r_{2}\right)\right]\right\}}{\partial r_{2}^{2}}
$$

which may be written as follows:

$$
\frac{d^{2} U^{T}}{d r_{1}^{2}}+\frac{2}{r_{1}} \frac{d U}{d r_{1}}=\frac{d^{2} V}{d r_{2}^{2}}+\frac{2}{r_{2}} \frac{d V}{d r_{2}}
$$

The first member of this equation is a function of $r_{1}$ alone and the second of $r_{2}$ alone. Hence we may set each member equal to the same constant and integrate each equation so obtained.

At this point Dr. Bonacini says: "In questa relazione il primo membro è funzione della sola $r_{1}$ ed il secondo della sola $r_{2}$, bisognerà quindi che l'uno e l'altro siano uguali a zero." By setting each member equal to zero and integrating, he was led to his erroneous conclusion.

Setting each member equal to the same constant $6 c$, we have

$$
\begin{aligned}
& \frac{d^{2} U}{d r_{1}^{2}}+\frac{2}{r_{1}} \frac{d U}{d r_{1}}=6 c, \\
& \frac{d^{2} V}{d r_{2}^{2}}+\frac{2}{r_{2}} \frac{d V}{d r_{2}}=6 c .
\end{aligned}
$$

Since these equations have exactly the same form, it is sufficient to consider one of them, say the first.

If we set $z=\log r_{1}$, or $r_{1}=e^{z}$, the equation becomes

$$
\frac{d^{2} U}{d z^{2}}+\frac{d U}{d z}=6 c \cdot e^{2 z}
$$


a linear differential equation with constant coefficients, of which the complete integral is

$$
U=c_{4}+c_{1} e^{-z}+c e^{2 z}
$$

$c_{1}$ and $c_{4}$ being constants of integration. Hence the complete integral of equation (8) is

$$
U=c_{4}+\frac{c_{1}}{r_{1}}+c r_{1}^{2},
$$

and similarly the complete integral of equation (9) is

$$
V=c_{5}+\frac{c_{2}}{r_{2}}+c r_{2}^{2} \text {, }
$$

where $c_{2}, c_{5}$ are constants of integration. And therefore the potential function $P$ is

$$
P=c r_{1}^{2}+c r_{2}^{2}+\frac{c_{1}}{r_{1}}+\frac{c_{2}}{r_{2}}+c_{3},
$$

which shows that the forces directed toward the two fixed centers are of the form first introduced by Lagrange, when the motion takes place in a fixed plane passing through the fixed centers of force.

To extend this to the general case of motion in space it is only necessary to remark that the linear element has the same form as before and the potential function differs only by the additional term

$$
-\frac{1}{2} \frac{a^{2}}{r^{2}}
$$

where $r$ denotes the distance of the moving point from the line of centers and $a$ is the constant of areas described by $r$ as it rotates about the line of centers. In elliptic coordinates this term becomes

$$
-\frac{1}{2} \frac{a^{2}}{r^{2}}=\frac{a^{2} a^{2}}{\sigma^{2}-\delta^{2}}\left\{\frac{1}{\sigma^{2}-a^{2}}-\frac{1}{\delta^{2}-a^{2}}\right\},
$$

which is itself of the required form. Hence the potential function for the general case can be put into the form (4), which form is necessary and sufficient for the separation of the variables in the equations of motion.

Princeton, New Jersey,

February 14, 1905. 